\title{
Mexican American Health Issues for the 21st Century
}

\author{
Paul Lopez \\ California State University, Chico
}

\begin{abstract}
This paper addresses some of the more important health issues affecting the Mexican American community in the 21 st century. These health issues are the lack of access to affordable health care and health insurance, and the lack of health research on the Mexican American community.
\end{abstract}

(C) 2003 Californian Journal of Health Promotion. All rights reserved.

Keywords: Mexican Americans, Migrant Workers, Health, Immigration

\section{Introduction}

The health of farm workers and that of Mexican Americans who makeup a majority of farm workers in California cannot be taken for granted. Many obstacles remain, far too many to list here, but are the focus of a Mexican-USA Border Health CD-ROM scheduled to be published in June 2003 by the California State University, Chico. These obstacles are economic, political, and social problems that will continue to grow due to three factors; the high fertility rate among Mexican Americans that continue to out pace other ethnic groups in the United States (Davis \& Brown, This Issue); larger average family size than other groups; and continued migration from Mexico, increasing the number of Mexicans living in the United States each year (Massey, Durand, Malone, \& Buch, 2002). The conditions will not disappear soon. On the contrary, Mexican Americans will continue to increase in population size according to the latest predictions of the U. S. Census.

Mexican American health issues for the 21st Century are: 1) the lack of access to affordable health care and health insurance, and 2) the lack of health research on Mexican American community.

\section{Lack of Access to Affordable Health Care \& Health Insurance}

The fear among farm workers of losing their jobs is a serious one. Indeed, for farmer workers, such as Martin Gonzalez who works in
Arbuckle, CA., he can't afford to miss work even when he is ill (Furillo, 2001). Being caught between keeping their jobs and staying home for several days because they are sick, farm workers usually have to choose to go to work despite being ill. This is only one aspect of not having adequate health care. The shortage of rural physicians and the distance farm workers must drive to visit one are prohibitive. Other problems they face problems are not having licenses to drive or insurance to drive to the nearest doctor, or the nearest medical facility not accepting the insurance they have. The prohibitive cost of medical or dental insurance, when available, also means many farm workers go without health insurance and so becoming ill is not even an option when they can afford treatment.

A recent study by the University of California (Furillo, 2001) found that immigrant farm workers from Mexico would be healthier had they stayed in Mexico rather than migrating north to work. Comparing undocumented farm workers from Mexico and legal farm workers from Mexico, the study found that Mexican legal resident farm workers endured more health problems. Among some of the health problems associated with immigrant farmer workers from Mexico were high blood pressure, high cholesterol and obesity. Some of the factors for the poor health and healthcare accessibility of farm workers, was due to a shift in diets toward more junk foods, language/cultural barriers and 
spending more time in United States, where gaining access to health care can be a problem. Mexican Americans, and farm workers in particular are also subject to an additional range of environmental and occupational hazards based upon where they live and work.

\section{Lack of Health Research on Mexican American Community}

According to David Hayes-Bautista (2002), health research has been primarily focused on non-Hispanic white male populations. As such, the results only reflect on non-Hispanic white male's illness patterns and successful treatments. In the state of California, the non-Hispanic white male is now in the minority. In 1998, nearly half the newborns in the state of California were Latino. However, despite the increased presence of Latinos in California, the health care model still reflects the norms of non Hispanic white males. In order to remedy that problem, health care research and practitioners must address the health of more than one racial population. Without a proper set of heath measures that address Mexican Americans concerns, Mexican Americans will continue to be underserved and this reflected in the sort life-span of Latinos, particularly in certain occupations, such as farm work.

Continued research on the health patterns of Mexican Americans is crucial. Far too many health problems continue to impact the Mexican American community. From the lack of access to insurance and doctors, unhealthy diets, language and cultural barriers in treatment, and chronic medical conditions that go undiagnosed, unstudied and untreated (Brown \& Hongjian, 2002). With Mexican Americans continuing to grow demographically in the State of California and other parts of the United States, these problems affect not only the Mexican American community, but the nation as a whole. We can continue to follow these ineffective historical paths or begin to provide new insights into the health care problems and solutions for the Mexican American community.

\section{References}

Brown, E. R., and Hongjian, Y. (2002). Latinos' access to employment-based health insurance. In Marcelo M. Suarez-Orozco and Mariela M. Paez (Eds.), Latinos: Remaking America. Berkeley: University of California Press.

Davis, C. A., and Brown, J. J. (2002). Recent trends in California Hispanic fertility rates - a comparative analysis. Californian Journal of Health Promotion, 1(2), 78-87.

Furillo, A. (2001). Legal immigrants suffer from greater chronic health problems, a new UC study reveals. Sacramento, CA: The Sacramento Bee.

Hayes-Bautista, D. E. (2002). The Latino health research agenda for the twenty-first century. In Marcelo M. Suarez-Orozco and Mariela M. Paez (Eds.), Latinos: Remaking America. Berkeley: University of California Press.

Massey, D., Durand, J., Malone, N. J., and Buch, A. J. (2002). Beyond smoke and mirrors: Mexican immigration in an era of economic integration. NY: Russell Sage Foundation.

$\underline{\text { Author Information }}$

Paul Lopez, $\mathrm{PhD}$

Department of Sociology

California State University, Chico

E-Mail:plopez@,csuchico.edu 